\title{
Covert pied-piping in English multiple wh-questions ${ }^{*}$
}

Hadas Kotek \& Michael Yoshitaka Erlewine, Massachusetts Institute of Technology To appear in Linguistic Inquiry

In this paper we argue for the existence of covert pied-piping in wh-questions through a previously unnoticed pattern of intervention effects in superiorityobeying English multiple wh-questions. We show that the preference of covert pied-piping is for movement of larger constituents, unlike overt pied-piping. We argue that this discrepancy stems from conflicting requirements of PF and LF: overt pied-piping feeds both LF and PF, but covert pied-piping feeds LF only. The study of covert pied-piping thus reveals the true preference of LF and Core Syntax with regard to pied-piping: larger pied-piping constituents are preferred over smaller ones. This preference can be overridden by certain PF constraints that apply to overt pied-piping.

Keywords: pied-piping, covert movement, multiple wh-questions, intervention effects, focus alternatives

\section{Introduction}

Much recent work on syntactic and semantic theory has debated the status of covert movement in grammar. At the same time, much empirical work has been done to better describe and explain the pied-piping observed with overt wh-movement. In this paper we ask the question: Does covert wh-movement also trigger pied-piping? We argue that the existence of covert pied-piping can be detected through the use of focus intervention effects (Beck, 2006; Beck and Kim, 2006; Cable, 2007; Grohmann, 2006; Kotek, forthcoming; Tomioka, 2007; Mayr, 2010; Sauerland and Heck, 2003). We present a novel pattern of focus intervention

\footnotetext{
"For helpful discussion, we thank David Pesetsky, Martin Hackl, Danny Fox, Irene Heim, Maziar Toosarvandani, Ivona Kučerova, Isaac Gould, Sasha Podobryaev, Coppe van Urk, and audiences at NELS 43 and the 2013 LSA. We would also like to thank Jay Keiser and the anonymous LI reviewers for their constructive criticisms and suggestions. All errors are each other's.
} 
effects in superiority-obeying English multiple wh-questions, which we argue is evidence for the existence of covert pied-piping.

Adopting the theory that focus intervention effects occur when the interpretation of a wh-phrase is interrupted by certain focus-sensitive interveners (Beck, 2006), we show that the logic of intervention can be used to diagnose areas in the derivation in which RoothHamblin focus alternatives are computed. We then use this diagnostic to investigate the status of the (phonologically) in-situ wh-phrase in superiority-obeying English wh-questions such as those in (1). In such questions, it has been argued that the lower wh covertly moves to C by LF (Karttunen, 1977; Huang, 1982; Hagstrom, 1998; Pesetsky, 2000; Beck, 2006; Cable, 2007, 2010).

\section{(1) No causes intervention effect in superiority-obeying multiple question:}
a. $\checkmark$ Which student read a book from which library?
b. ${ }^{*}$ Which student read no book from which library?

Building on previous work by Sauerland and Heck (2003), Cable (2007) shows that focus intervention effects occur inside overtly pied-piped constituents. We argue that the ungrammaticality of $(1 b)$ is the result of a focus intervention effect inside a covertly pied-piped constituent. That is, the surface-in-situ wh-word which covertly moves at LF and pied-pipes a constituent containing the intervener no. The contrast in (1) and other examples presented in section 3 is neatly predicted by the semantics of pied-piping constituents proposed by Cable (2007), together with Beck's (2006) system of focus intervention.

Furthermore, we demonstrate that the constituent pied-piped with wh corresponds to the largest among the corresponding overt pied-piping possibilities for a parallel single whquestion. This, we argue, reveals the true nature of pied-piping: unlike overt pied-piping, which is subject to restrictions from both LF and PF, covert pied-piping is guided only by LF. The investigation of covert pied-piping, then, shows us the true preference of LF and Core Syntax with regard to pied-piping: LF chooses the largest possible constituent as its preferred candidate for movement. In overt pied-piping, however, this choice can be 
overridden by certain PF constraints (Heck, 2008, 2009).

The paper is structured as follows: in section 2 we provide background on Beck's (2006) theory of focus intervention effects in wh-questions, and on its extension to overt piedpiping constructions (Cable, 2010). We present the use of focus intervention effects as a diagnostic for covert movement versus Rooth-Hamblin focus alternative computation. In section 3 we show that assuming that intervention correlates with focus alternative computation, the data motivates the existence of covert pied-piping. We show that covert wh-movement prefers to pied-pipe larger constituents, in contrast to overt wh-movement which tends to prefer smaller pied-piping constituents. In section 4 we argue that the different preferences for overt vs. covert pied-piping result from conflicting constraints on the PF and LF interfaces: the true preference of LF and Core Syntax is for larger pied-piping constituents, but this can be overridden by PF constraints, often result in smaller overt pied-piping. Section 5 is the conclusion.

\section{Background: Intervention effects in overt pied-piping}

In this section we present Beck's (2006) theory of focus intervention effects for English questions and its extension to intervention inside pied-piping constituents (Cable, 2007, 2010). We will motivate the use of intervention effects as a diagnostic tool for regions in the derivation of a question in which covert movement has occurred and regions in which Rooth-Hamblin alternatives are computed. We will then use this diagnostic to address the question: Does covert pied-piping exist and, if so, how large is it? The answer to that question will be the main goal of section 3 .

\subsection{Beck's (2006) theory of focus intervention effects}

Pesetsky (2000) observes a correlation between superiority (Kuno and Robinson, 1972; Chomsky, 1973, a.o.) and intervention effects in English multiple questions with D-linked whphrases. Motivating examples are given in (2): (2a-b) show that English generally allows 
both superiority-obeying questions and superiority-violating questions with D-linked whphrases. Examples (2c-d) show that when certain interveners-here, negation-are introduced into the questions, only the superiority-obeying structure is grammatical. The superiorityviolating question is ungrammatical. ${ }^{1}$

(2) D-linked questions can violate superiority but superiority-violating questions are sensitive to intervention:
a. Which boy read which book?
$\checkmark$ superiority-obeying, no intervener
b. Which book did which boy read
? $\checkmark$ superiority-violating, no intervener
c. Which boy didn't read which book?
$\checkmark$ superiority-obeying, intervener
d. $\quad$ *Which book didn't which boy read
? $\quad$ * superiority-violating, intervener

Other operators that give rise to an intervention effect include only, very few, never, and no one, as shown in examples (3-6) below from Pesetsky (2000). ${ }^{2}$

\footnotetext{
${ }^{1}$ Pesetsky (2000) reports that in cases of intervention in multiple wh-questions such as (2), many speakers report that the question is ungrammatical while some others report that the question's single-pair reading is maintained (ia) but its pair-list reading is lost (ib). For this reason, the multiple wh-questions which are crucial to our argumentation (section 3) are presented with explicit contexts which make their pair-list readings appropriate. See Dayal 2002 for more discussion of the semantics of the readings, Pesetsky 2000 for a discussion of the judgments.

(i) Single-pair and pair-list readings of Which boy didn't read which book?:

a. John didn't read Robinson Crusoe.

b. John didn't read Robinson Crusoe, Bill didn't read Moby Dick, and Fred didn't read Don Quixote.

${ }^{2}$ The characterization of the set of interveners has been a source of debate in recent literature. Beck (2006) and Beck and Kim (2006) have identified a number of focus-sensitive operators, including only, also, even, and negation, as a relatively cross-linguistically stable set of interveners. The Beck (2006) theory of intervention is discussed and adopted here.

We note that Büring (1996a) argues that sentential negation is not a focus-sensitive operator, possibly raising a problem for the theory in Beck (2006). Büring (1996a) argues that apparent focus-sensitive effects of the interpretaiton of negation in declaratives can be reduced to sentences with different prosody being congruent to different questions under discussion. (A similar argument is made in Beaver and Clark (2008, chapter 3).) We note, however, that these arguments are based solely on the contribution of negation in declaratives. A full investigation of the potential effects of focus on negation in interrogatives is outside of the scope of this paper. Here we simply follow Pesetsky (2000) and Beck (2006) who show that sentential negation in English patterns together with the other items as an intervener.

Other authors have observed that the set of interveners can vary across languages and have proposed correspondingly different theories for intervention itself. See discussion of analyses of interveners as anti-topic items (Grohmann, 2006; Tomioka, 2007) in footnote 11, and Mayr's (to appear) analysis of interveners as nonadditive items in footnote 17 below.
} 
(3) Intervention effect with only only affects superiority-violating question:
a. Which girl did only Mary introduce to which boy?
b. * Which boy did only Mary introduce which girl to ? ?

(4) Intervention effect with very few only affects superiority-violating question:
a. Which picture did very few children want to show to which teacher?
b. * Which teacher did very few children want to show which picture to _ ?

(5) Intervention effect with never only affects superiority-violating question:
a. Which student did he never claim would talk about which topic?
b. * Which topic did he never claim which student would talk about _ ?

(6) Intervention effect with no one only affects superiority-violating question:
a. Which book did no one give to which student?
b. * Which student did no one give which book to _ ?

To explain the relation between superiority and intervention effects, Pesetsky (2000) argues that superiority-obeying questions and superiority-violating questions are derived from different structures. Of particular importance is the location of the (phonologically) in-situ wh-phrase: Pesetsky proposes that the in-situ wh-phrase covertly moves to C at LF in a superiority-obeying question, but remains in its base-generated position in a superiorityviolating question. The resulting structures are given in $(7 a-b)$ :

(7) LF representations of superiority-obeying and superiority-violating questions:
a. [СР $w h_{1} w h_{2}\left[\right.$ C [TP $\left.\left.\left.\ldots t_{1} \ldots t_{2}\right]\right]\right]$

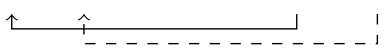
superiority-obeying
b. $\left[\mathrm{CP} w h_{2}[\underbrace{\mathrm{C}}[\underbrace{\mathrm{TP}} \ldots h_{1} \ldots t_{2}]]\right]$
superiority-violating

When the (phonologically) in-situ wh-phrase does not undergo covert movement $\left(w h_{1}\right.$ in 7b), it is interpreted via Rooth-Hamblin alternative computation (Hamblin, 1973; Kratzer and 
Shimoyama, 2002, a.o.). ${ }^{3}$ These two strategies for establishing a relation between the interrogative $C$ and wh and assigning wh a semantics are schematized in $(8 \mathrm{a}, \mathrm{b})$ respectively. Both strategies have been independently proposed in the literature for the analysis of (phonologically) in-situ wh-phrases, and are widely used in current research on the syntax and semantics of multiple wh-questions.

(8) Interpretation of wh using covert movement and using Rooth-Hamblin alternatives:

a.

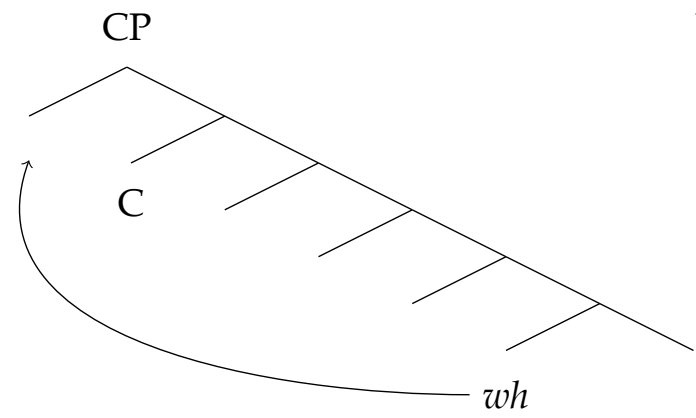

b.

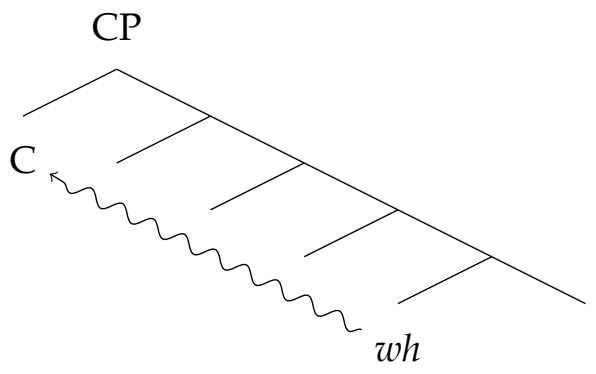

Rooth-Hamblin alternatives are a parallel mode of semantic interpretation, where a focussemantic value can be computed compositionally for each syntactic node, in parallel to its ordinary semantic value (Hamblin, 1973; Rooth, 1985, 1992). This computation has been argued to supply operators such as focus operators and question complementizers with a relevant set of alternative denotations or propositions. Consider the LF representation for the wh-in-situ pseudo-English question "Alex likes who?" in (9) below. Focus-semantic values-also referred to as alternatives-are given for each node.

\footnotetext{
${ }^{3}$ Here and throughout, we use straight arrows to indicate movement and curly arrows to indicate areas in which Rooth-Hamblin alternatives are computed. These curly arrows are used here as a notational convenience only. Dashed arrows indicate covert movement.
} 
(9) A toy LF of question interpretation through Rooth-Hamblin alternative computation:

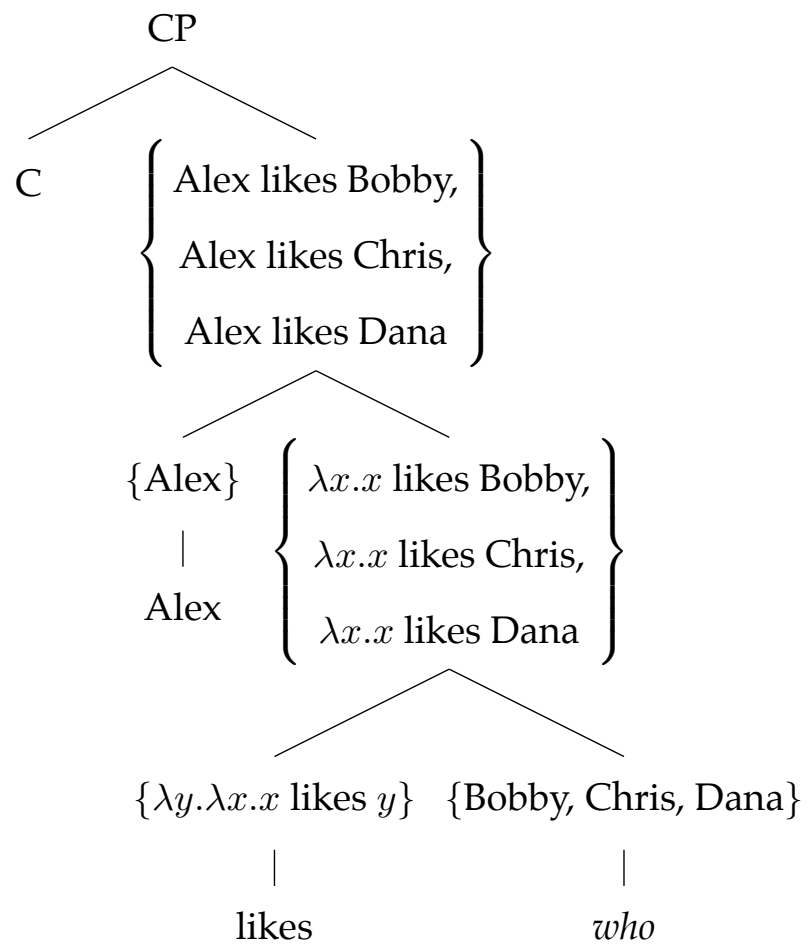

In (9), the wh-phrase who has a focus-semantic value corresponding to relevant individuals in its domain-here, the animate individuals Bobby, Chris, and Dana. ${ }^{4}$ These alternatives compose pointwise at each nonterminal node, ${ }^{5}$ resulting in the complement of the interrogative $C$ having a set of propositions as its focus-semantic value. ${ }^{6}$ The interrogative $\mathrm{C}$ then computes the question denotation using these alternatives in its complement, so that these alternative propositions correspond to possible (weak) answers to the question.

${ }^{4}$ The semantics of what and who in Beck (2006) are given below:

(i) Semantics of what:

ordinary semantics: $\llbracket w h a t \rrbracket=$ undefined

focus-semantics: $\llbracket$ what $\rrbracket^{f}=\left\{x_{\langle s, e\rangle}: x \notin\right.$ human $\}$

(ii) Semantics of who:

ordinary semantics: $\llbracket w h \rrbracket=$ undefined

focus-semantics: $\llbracket w h o \rrbracket^{f}=\left\{x_{\langle s, e\rangle}: x \in\right.$ human $\}$

${ }^{5}$ In this paper we will not be presenting computations of Rooth-Hamblin alternatives beyond the toy example in (9). We refer the reader to Hamblin $(1973)$; Rooth $(1985,1992)$ and subsequent work on the technical details of Rooth-Hamblin (focus) alternative computation.

${ }^{6}$ The semantic denotations here must be interpreted intensionally. World variables are not illustrated here to simplify the presentation. 
In this way, the focus-semantic value provided by the in-situ wh-phrase is interpreted by the interrogative $\mathrm{C}$. This yields the appropriate question semantics without establishing a syntactically local relationship between the wh-phrase and C.

Beck (2006) argues that the Rooth-Hamblin alternative computation strategy of interpreting wh-phrases is sensitive to focus intervention effects:

\section{(10) Description of a focus intervention effect:}

When a focus-sensitive operator occurs between an LF-in-situ wh-word and its associated complementizer, the operator disrupts the projection of the wh-word's alternatives. As a result, the wh-word cannot be interpreted by $\mathrm{C}$, and the derivation crashes.

This illicit configuration is schematized in (11b). In essence, the problem is one of Minimality. The alternatives projected from the wh-word must be interpreted by the associated complementizer. However, focus-sensitive operators also interpret alternatives in their scope (Rooth, 1985, 1992). When a focus-sensitive operator (represented as intervener) intervenes in between the in-situ wh-word and the interpreting complementizer, the alternatives projected by the the wh-word will be interpreted by the intervener instead of by $\mathrm{C}$, thus disrupting the question interpretation. ${ }^{7,8}$

\footnotetext{
${ }^{7}$ It is worth noting that for intervention effects to occur as theorized by Beck (2006) in structures such as (11b), the alternatives used by focus-sensitive operators (à la Rooth) and the alternatives used for question interpretation (à la Hamblin) must be the same formal objects. This equivalence of focus alternatives and whinterpreting alternatives is therefore an important theoretical claim of Beck's (2006) system. This formal equivalence reflects the long-observed similarities between wh and focus realization cross-linguistically, including in syntax and prosody (Horvath 1986; Culicover 1992; Simpson 2000; Drubig 2000; Arregi 2002; Szendrôi 2003; Simpson and Bhattacharya 2003; Truckenbrodt 2013 and many others). However, see for example Mayr (to appear) for arguments against this approach.

${ }^{8}$ Note that there may also be another problem when interpreting configuration (11b). Standard focussensitive operators utilize both the focus-semantic value and the ordinary semantic value for their interpretation (Rooth, 1985, 1992), but the ordinary semantic value for the complement of the intervener in (11b) will be undefined (see footnote 4). See Beck (2006) for more technical discussion.
} 
(11) Focus alternative computation, but not covert movement, is sensitive to intervention effects:

a. $\mathrm{CP}$

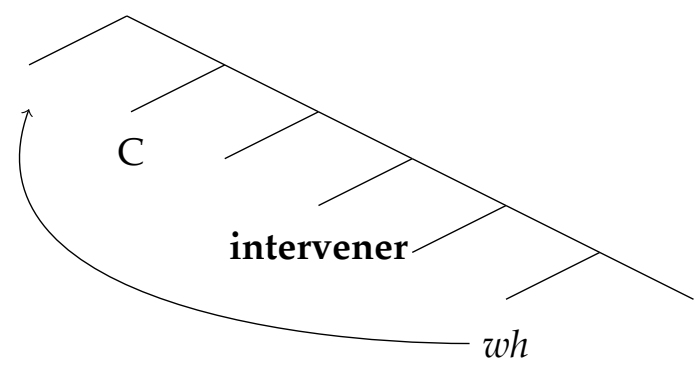

b. * $\mathrm{CP}$

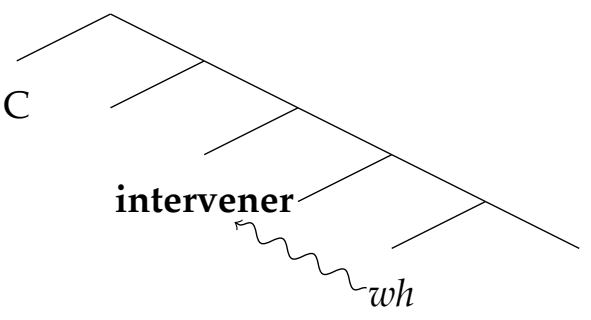

The covert movement strategy of interpreting wh-phrases, on the other hand, is immune from intervention effects: intervention only affects wh-phrases that project focus alternatives but not traces of wh-movement (11a).

The Beck (2006) schema for intervention effects between an in-situ wh-phrase and C is summarized in (12). Given this schema for intervention effects, we predict such effects to arise in superiority-violating questions when an intervener is introduced between the in-situ wh-word and C. We expect not to find intervention effects for superiority-obeying questions, since all wh-phrases in such questions move to $C$ by LF. These structures are illustrated in (13) below. This is consistent with the findings of Pesetsky (2000).

(12) Intervention schema with in-situ wh-phrases (Beck, 2006):

${ }^{*} \mathrm{LF}:[$ C ... intervener ... wh ]

(13) The interaction of superiority and interveners at LF (cf 7):

a. Superiority-obeying questions: no intervention effects

$\checkmark\left[\mathrm{CP} w h_{1} w h_{2}\left[\right.\right.$ C [TР $\ldots$ intervener $\left.\left.\left.\ldots t_{1} \ldots t_{2}\right]\right]\right]$

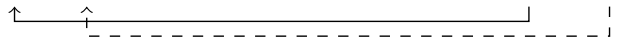

b. Superiority-violating questions: intervention effects

$$
\left.{ }^{*}\left[\mathrm{CP} w h_{2}\left[\text { C [ [тр ... intervener } \ldots w h_{1} \ldots t_{2}\right]\right]\right]
$$


Following this logic, focus intervention effects can diagnose whether or not covert whmovement has occurred in the derivation of a question: the presence of an intervention effect teaches us that a (phonologically) in-situ wh-phrase is interpreted through RoothHamblin alternative computation, and the lack of an intervention effect teaches us that the wh-phrase has covertly moved above the scope of the intervener. ${ }^{9}$

\subsection{Intervention effects in pied-piping constituents and Cable's theory of pied- piping}

Cable $(2007,2010)$ shows that intervention effects also occur in superiority-obeying English questions inside pied-piping constituents (14). This work builds on a study by Sauerland and Heck (2003) who show a similar effect in German (15).

Intervention effect in English pied-piping (Cable, 2007):

a. ? [A picture of which president] does Jim own _ ?

b. * [No pictures of which president] does Jim own _ ?

c. * [Few pictures of which president $]$ does Jim own __ ?

d. * [Only PICTURES of which president] does Jim own _ ?

(15) Intervention effect in German pied-piping (Sauerland and Heck, 2003):

Fritz möchte wissen [[ein / ${ }^{*}$ kein wie schnelles Motorrad] du fahren darfst].

Fritz wants know a/no how fast motorbike you drive may

'Fritz wants to know how fast a/ *no motorbike you are allowed to drive.'

Cable $(2007,2010)$ argues that the presence of intervention effects inside pied-piping constituents is explained if wh-words inside such constituents are interpreted via RoothHamblin alternative computation between wh and the edge of the pied-piping. Cable's

\footnotetext{
${ }^{9}$ See also Kotek (2013); Erlewine and Kotek (to appear) on the use of focus intervention effects to diagnose regions of Rooth-Hamblin alternative computation, in particular in wh-questions with islands and Association with Focus constructions, respectively.
} 
theory is designed to explain the presence and size of pied-piping in wh-questions in different languages. In this theory, wh-movement is recast as QP-movement: in the construction of a wh-question, a Q-particle (silent in English but overt in some languages) is adjoined to a particular wh-containing constituent. The resulting QP is targeted by the interrogative $\mathrm{C}$ for Agree and Attract operations. Movement of a QP containing more than just the wh-word leads to what has previously been described as pied-piping.

The size of pied-piping is then determined by the position to which Q adjoins. In (16a) below, Q adjoins to the wh-containing DP “a picture of which president”; in (16b), Q adjoins to the PP "of which president"; in (16c), Q adjoins to the which-phrase DP "which president." The positions to which $\mathrm{Q}$ can adjoin are restricted in some languages by a local Agree operation between wh and Q. In English, Q cannot adjoin to constituents larger than in (16a). ${ }^{10}$

\section{(16) Different sizes of pied-piping corresponds to different positions of Q-adjunction:}

Base structure: C Jim owns (Q) a picture (Q) of $(Q)$ which president
a. ? [QP Q A picture of which president] does Jim own ?
b. [QP Q Of which president] does Jim own a picture _ ?
c. [QP $\mathrm{Q}$ Which president] does Jim own a picture of _ ?

In the derivation of a question like (16), then, two steps occur: first, a movement step of QP to the specifier of the interrogative complementizer, and second, inside QP, the $w h$-word itself is interpreted via Rooth-Hamblin alternative computation between wh and Q.

\section{(17) Interpreting (16a) through both movement and alternative computation:}

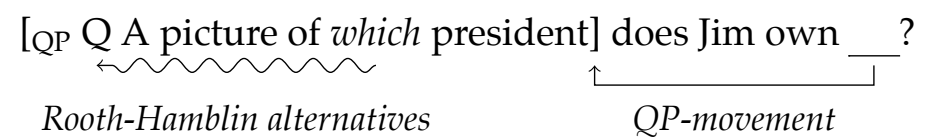

\footnotetext{
${ }^{10}$ Cable argues that English is a Limited Pied-Piping Language, defined as follows:

(i) Limited Pied-Piping Language (Cable, 2010):

A language where a wh-word cannot be dominated in a pied-piped phrase by either an island or lexical category.

Cable (2010, pp. 190ff) does recognize and discuss the availability of pied-piping with larger constituents, such as (16a), in English.
} 
Building on Beck (2006), Cable argues that this alternative computation inside QP is sensitive to intervention effects, as in the schema in (18). That is, if a focus-sensitive operator occurs between $w h$ and $Q$, it will interrupt the projection of alternatives from $w h$ to $\mathrm{Q}$ and lead to the same problem that is caused if an intervener occurs between an LF-in-situ wh and $\mathrm{C}$ (the Beck schema, 12). ${ }^{11}$

\section{Intervention schema for wh-pied-piping (Cable, 2007, cf Sauerland and Heck 2003):}

$$
{ }^{*}[\mathrm{QP} Q \ldots \text { intervener } \ldots \text { wh } \ldots]_{i} \ldots t_{i} \ldots
$$

Cable argues that the configuration in (18) explains the ungrammaticality of examples $(14 \mathrm{~b}-\mathrm{d})$ : an intervener-no, few or only-occurs between wh and the edge of the piedpiping constituent, where $\mathrm{Q}$ is merged, and blocks the transmission of Rooth-Hamblin

\footnotetext{
${ }^{11}$ We note that serveral alternatives to Beck's (2006) theory of intervention effects have been proposed in the recent literature. Although such theories exist, they have been developed for other languages and have not been applied to the English data. Furthermore we show that the application of these theories to our data presents problems that we believe are unsolvable. In this footnote we discuss two which identify interveners as anti-topic items-items that cannot be topicalized or backgrounded. See footnote 17 below for another alternative approach, Mayr (to appear).

Grohmann (2006) proposes a theory of intervention effects in German under which intervention is caused when an anti-topic item occurs between two wh-phrases in the CP periphery. We note that this theory does not clearly extend to English, as discussed by Grohmann himself (see Grohmann 2006 pp. 13, 24), and that furthermore the theory predicts no intervention effects inside pied-piped constituents, because intervention is caused when interveners move to a topic position in the CP periphery, but not when they move inside DPs.

Tomioka (2007) proposes a prosody-based account of intervention effects in Japanese and Korean single wh-questions, according to which intervention occurs when an anti-topic item occurs to the left of a wh-word in a question, with these interveners including items such as NPIs and disjunctions. This theory does not clearly extend to English, because it crucially relies on prosodic properties of Japanese and Korean questions, which English does not share. More worrisome, we believe that Tomioka (2007) makes incorrect predictions for Japanese questions with configurations such as the ones discussed in our paper. Examples (ia-b) below are judged by speakers to be similarly (un)acceptable. In (ia) an intervener dareka 'someone' occurs above the wh-word nani 'what,' which is predicted by Tomioka to cause an intervention effect. Native speakers report that (ia) may be slightly degraded, but not clearly ungrammatical like baseline Japanese intervention examples in Tomioka (2007). In (ib) we have an order that is predicted by Tomioka to be acceptable, because the wh-word occurs before the intervener, but this sentence is not judged by speakers to be better than its counterpart in (ia). Consequently, we are unsure how to extend Tomioka's (2007) theory to our test cases.
}

(i) Data with wh-word and intervener inside a single DP, unexplained by Tomioka (2007):

a. ? [Dareka-no [nan-no shashin]]-o mi-ta no? someone-GEN what-GEN picture-ACC see-PAST Question

'[Someone's [picture of what]] did you see?'

b. ? [Dare-no [nanika-no shashin]]-o mi-ta no? who-GEN something-GEN picture-ACC see-PAST Question

'[Whose [picture of something]] did you see?' 
alternatives between $w h$ and $Q$.

Cable offers further evidence to show that (18) is the relevant structural configuration for these contrasts-i.e., that an intervener between the wh and the edge of the pied-piping $(\mathrm{Q})$ is the source of ungrammaticality in $(14 b-d)$. For example, the intervention effect in $(14 b)$ can be avoided by pied-piping a smaller constituent which does not include the potential intervener (19). In addition, placing an intervener inside QP but below the wh-word does not trigger intervention (20).

\section{(19) No intervention if the intervener is not inside the pied-piping constituent:}
a. $\quad{ }^{*}[\mathrm{QP} Q \mathrm{Q}$ No pictures of which president] does Jim own _
b. $\quad \checkmark[\mathrm{QP}$ Q Of which president] does Jim own no pictures _ ?
c. $\checkmark[\mathrm{QP} Q$ Which president] does Jim own no pictures of _ ?

(20) No intervention if the intervener is inside pied-piping constituent but below $w h$ : $\checkmark$ [Which picture containing no presidents] does Jim own $\quad$ ?

In this paper we investigate the syntax and semantics of multiple wh-questions. Following the work presented in section 2.1, we assume that the (phonologically) in-situ whphrase in a superiority-obeying question moves to $C$ by LF. The question that we set out to answer in this paper is: does covert wh-movement pied-pipes material along with the whword? And, if so, how much? We will use the presence or absence of intervention effects inside potentially covertly pied-piped constituents as a diagnostic for regions where covert movement has occurred and regions where Rooth-Hamblin alternatives are computed. We elaborate on this logic in section 3, where we present a novel pattern of intervention effects in English superiority-obeying questions. 


\section{Diagnosing covert pied-piping}

In this section we will argue based on the pattern of focus intervention effects in English multiple wh-questions that covert pied-piping exists, and furthermore that covert piedpiping of larger constituents is preferred over that of smaller constituents. Our main focus will be on questions such as (21) below, where we assume that the (phonologically) in-situ wh-phrase moves to C by LF. ${ }^{12}$

(21) Superiority-obeying multiple question: the lower wh covertly moves to C at LF: Which student ... which... C__ read a book from which library?

Given that in superiority-obeying questions the in-situ wh-phrase covertly moves to C by LF, we are interested in knowing if covert wh-movement pied-pipes material along with the wh-word, and if so-how much. At least three different sizes of covertly pied-piped constituents could be available in (22), corresponding to the possible sizes of overt piedpiping in examples such as (16) above. ${ }^{13}$

Options for covert pied-piping at LF, based on the options for overt pied-piping: Which student read a book from which library?

a. [QP Q Which student $]_{1}[\mathrm{QP} Q \mathrm{Q} \text { book from which library }]_{2} \mathrm{C} t_{1}$ read $t_{2}$

b. [QP Q Which student $]_{1}[\mathrm{QP} Q \mathrm{Q} \text { from which library }]_{2} \mathrm{C} t_{1}$ read a book $t_{2}$

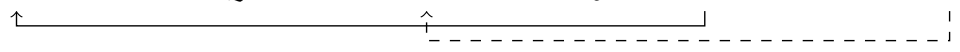

c. [QP $\mathrm{Q}$ Which student $]_{1}[\mathrm{QP} \mathrm{Q} \text { which library }]_{2} \mathrm{C} t_{1}$ read a book from $t_{2}$

\footnotetext{
${ }^{12}$ Although we present this as an assumption to facilitate the discussion, below we will show that the pattern of intervention effects that we observe further supports the conclusion that the lower wh could not be interpreted in-situ in English superiority-obeying questions.

${ }^{13}$ See discussion in section 2.2 and Cable (2010) for arguments that Q can't be merged with VP and larger constituents in English.
} 
The movement of the lower QPs in (22) is covert, and thus all three of the LF representations in (22) correspond to the same PF string: "which student read a book from which library?". Unlike with overt pied-piping, the choice of covert pied-piping size is not detectable in the resulting linearization.

We instead propose the use of focus intervention effects as a diagnostic for the existence and size of covert pied-piping. The different sizes of covert pied-piping in (22) corresponding to different QP sizes—predict different regions that should be sensitive to intervention effects.

The logic of this diagnostic is as follows. As we saw in section 2.2, in cases of overt piedpiping, the region inside the pied-piping constituent $(\mathrm{QP})$ and above the wh-word is intervenable; that is, the insertion of a focus-sensitive operator in this region leads to ungrammaticality $\left(18^{\prime}\right.$ below). In the Cable $(2007,2010)$ theory for the semantic interpretation of pied-piping constituents, wh-phrases are interpreted by their Q-particle through RoothHamblin alternative computation, thus explaining why the region between the wh and $Q$ is intervenable under the Beck (2006) logic of intervention. Following Cable, we assume that covertly-moved QPs are also interpreted using this same semantic mechanism. Therefore, if covert pied-piping does occur, we predict a small region near and above the surface-insitu wh-word to be intervenable (23).

(18') Intervention in overt pied-piping (Cable, 2007, cf Sauerland and Heck 2003): [QP Q ...INTERVENABLE... wh ...] C ...

(23) Intervention in covert pied-piping:

$$
\underset{\uparrow}{\ldots \mathrm{C} \ldots . .} \underbrace{[\mathrm{Q} \ldots \mathrm{INTERVENABLE} \ldots}_{\mathrm{QP}} \text { wh ...] }
$$

The different covert pied-piping options in (22) predict different regions to be intervenable, represented by the gray shading in (24). (In (24) and subsequent examples, the lower QP is represented in-situ, to reflect the linearization at PF.) If the largest QP is chosen, (24a), 
the entire region between $a$ and $w h$ is intervenable. If the smaller QP in (24b) is chosen, only the preposition from is inside the intervenable region. If the smallest QP in (24c) is chosen, there is little or no intervenable region between $\mathrm{Q}$ and $w h$.

\section{(24) Different covert pied-piping options predict different intervenable regions:}

Which student read a book from which library?
a. [QP $\mathrm{Q}$ Which student] read [QP $\mathrm{Q}$ a book from which library].
b. [QP Q Which student] read a book [QP $\mathrm{Q}$ from which library].
c. [QP $\mathrm{Q}$ Which student] read a book from [QP $\mathrm{Q}$ which library].

In what follows, we will use the size of the intervenable region as a diagnostic for the presence of covert pied-piping and its size. We use the interveners no, only, and very few, placed inside regions suspected of being intervenable. If the presence of an intervener in our examples causes an intervention effect, the conclusion will be that the intervener occurs inside an intervenable region. We will show that the intervenable regions we find occur inside covertly pied-piped constituents — that is, between wh and Q (schema in 18) —and not between an in-situ wh and C (schema in 12). Since it has been argued that intervention effects only affect the pair-list reading of a question (Beck, 1996; Pesetsky, 2000; Kotek, 2013), we present each example in a context designed to bring out the pair-list reading of the multiple question and satisfy its presuppositions (Dayal, 2002). ${ }^{14}$

We begin with our baseline example (21), repeated below in (25) with a context supporting its pair-list interpretation. The question is reported to be grammatical and felicitous in this context.

\section{(25) Baseline: multiple question with pair-list reading}

a. Context: Over the break, every student read a book from a local library and submitted a book report. Each report gave the title of the book and which library

\footnotetext{
${ }^{14}$ Note that Reinhart (1998) develops a theory that allows for the interpretation of a multiple wh-question without requiring movement of the (phonologically) in-situ wh-phrase. However, this theory can only derive a single-pair reading of the question and not a pair-list reading (see Dayal 2002 for discussion). Crucially, the examples in this section are given in a pair-list context and thus cannot be interpreted using Reinhart's choice-function mechanism.
} 
it was borrowed from. You have read all the book reports. So tell me, what I want to know is:

b. $\checkmark$ Which student read a book from which library?

Next, we consider an example in which the determiner $a$ is replaced with the determiner no (26), which we saw to be an intervener in cases of overt pied-piping in section 2.2. Again, the question is preceded by a context designed to favor the pair-list reading of the question and satisfy its presuppositions. If no occurs inside an intervenable region, we expect this manipulation to lead to an intervention effect. The result, as reported by native speakers of English, is that the question is ungrammatical despite appearing in a context that should make it felicitous. That is, we observe an intervention effect. ${ }^{15}$

\section{(26) Intervention effect caused by the presence of no in the question:}

a. Context: Over the break, the students were assigned to go read one book each from every library in the area and submit a book report. No student completed the entire assignment; every student went to all but one of the libraries. You have read all the book reports. So tell me, what I want to know is:

b. $\quad$ *Which student read no book from which library?

The contrast between (26) and its baseline (25) tells us that the intervener no is in an intervenable region. ${ }^{16}$ Recall that different sizes of covert pied-piping predict different intervenable regions. In particular, no is an intervenable region if the largest pied-piping option was chosen: no book from which library (27a). If, however, a smaller pied-piping constituent is targeted for movement—from which library (27b) or which library (27c)—we expect no to be outside the intervenable region and therefore not cause an intervention effect. Therefore,

\footnotetext{
${ }^{15}$ We note that Cable (2007) reports examples similar to our (26) to be grammatical, cf. his example (81) on page 139. However, Cable does not report whether the question can be interpreted as having a pair-list reading or only a single-pair reading. As we have noted above, the single-pair reading of the question is indeed predicted to be possible, accounting for the judgment reported by Cable.

${ }^{16}$ Note that, for some speakers, the determiner no in object position is generally slightly degraded. Nonetheless, native speakers report a strong contrast with the example in (26) with the relevant reading, beyond what may be expected from simply having no in object position. Furthermore, this contrast is not limited to nofurther examples will show that other items in this position can also act as interveners. Therefore, this example constitutes one in a series of intervention effects in this configuration, rather than a confounding outlier.
} 
the intervention contrast observed in (26) is predicted by pied-piping of the largest option as in (27a) but not $(27 b-c)$.

\section{(27) Different covert pied-piping options predict different intervenable regions; only}

(27a) predicts (26):

Which student read no book from which library?
a. [QP Q Which student] read [QP Q no book from which library]?
b. [QP Q Which student] read no book [QP Q from which library]?
c. [QP Q Which student] read no book from [QP $\mathrm{Q}$ which library]?

Note that this effect is not a general effect attributable to the presence of a negative quantifier in the question. The example below, in which the quantifier less than three is used, is judged by speakers to be felicitous and grammatical in the context. ${ }^{17}$

\section{(28) No intervention effect with less than three:}

a. Context: Over the break, the students were assigned to go read three book each from every library in the area and submit a book report. No student completed the entire assignment; every student had one particular library from which they failed to read three books. You have read all the book reports. So tell me, what I want to know is:

b. $\quad \checkmark$ Which student read less than three books from which library?

Furthermore, we note that an intervention effect can be observed not only with no but also with only and with very few, as shown in (29-30) below. We note that the judgment with very few appears to be less sharp than with no and only. ${ }^{18}$

\footnotetext{
${ }^{17}$ Mayr (to appear) offers an alternative characterization to Beck's (2006) intervention effects, proposing that intervention occurs when a non-additive element has a wh-phrase in its scope. We believe that this theory may, in principle, predict intervention effects inside DPs. However, his theory predicts that all non-additive quantifiers, including less than $n$ should act as interveners. Data from Mayr suggest that this is indeed the case in German, but the native speakers we have consulted find a clear contrast between the example with no and the example with less than three in English. This finding thus constitutes a challenge to the generality of Mayr's theory and its extension to English.

${ }^{18}$ Much work on proportional determiners such as few argues that these determiners have three truthconditionally distinct readings, including the cardinal reading, the proportional reading and the so-called
} 


\section{(29) Intervention effect caused by the presence of only in the question:}

a. Context: At the flea market, a number of collectors are selling pictures and autographs of past presidents. For most presidents, they have successfully sold both pictures and autographs, but according to the records, every collector has one president for which they did not sell any autographs. You have read through all the records. So tell me, what I want to know is:

b. $\quad$ *Which collector sold only PICTURES of which president?

\section{Intervention effect caused by the presence of very few in the question:}

a. Context: We at McDonald's are testing three new toppings for burgers: cranberries, jicama, and natto. As a pilot, these toppings were offered at several branches around the world for one week only. At each branch, only two toppings sold thousands while the other sold about a hundred. Culinary tastes vary across the world, so there was no clear overall winner. You have looked at all the sales records. So tell me, what I want to know is:

b. ?? Which branch sold very few burgers with which topping?

With these results in mind, the main contrasts that we aim to explain are the minimal pairs in (31-32) below. We argue that these contrasts are the result of intervention effects, caused by placing the focus-sensitive interveners no and only between wh and the edge of a covertly pied-piped constituent that is at least as large as the DP headed by no and only. We acknowledge that the judgements behind the contrasts we present here are subtle. This is in part due to the complexity of even our baseline questions, as well as the relatively complex contexts that accompany these questions, in order to ensure that they are interpreted with the relevant (pair-list) reading. Despite this, we have found these contrasts to be robust reverse-proportional reading. The computation of two of these readings-the proportional and the reverseproportional-has been argued to involve focus, but the cardinal reading of few NP can be derived through a simple comparison of the cardinality of NP with a contextual standard. See Herburger (2000); Büring (1996b); Kotek et al. (2012) for discussion of the readings and their derivations. The example in the context we give is designed to be a felicitous use of very few only under the focus-sensitive proportional reading. However, it is possible that interference from a cardinal reading is making the judgment more difficult than in the other cases we consider. 
across a variety of elicitation and verification sessions.

(31) Minimal pair: no causes intervention effect in multiple question
a. $\checkmark$ Which student read a book from which library?
b. $\quad$ * Which student read no book from which library?

\section{(32) Minimal pair: only causes intervention effect in multiple question}
a. $\checkmark$ Which collector sold two pictures of which president?
b. $\quad$ *Which collector sold only PICTURES of which president?

Note that the ungrammaticality of $(31 b)$ is not due to a general negative island effect between the in-situ wh-word and C (Ross, 1984; Rizzi, 1990; Szabolcsi and Zwarts, 1993; Beck, 1995; Rullmann, 1995; Kuno and Takami, 1997; Fox and Hackl, 2006, a.o.). It has been observed that certain wh-phrases are unable to move across intervening negative elements. For example, in example (33), we see that movement of the manner wh-word how is ungrammatical over both sentential negation and the negative determiner no.

(33) Negative islands affecting how-movement (Szabolcsi and Zwarts, 1993):
a. * How didn't you think that I behaved_ ?
b. * How did no one think that I behaved _ ?

If the ungrammaticality of $(31 \mathrm{~b})$ were due to a negative island we would expect that any negation between the in-situ wh-phrase and $C$ would trigger a similar negative island effect. This is not the case. In example (34) below, we see that sentential negation (shown to trigger negative islands in (33a) above) does not trigger ungrammaticality, in contrast to (31b). Therefore the ungrammaticality of (31b) cannot be due to a so-called negative island effect.

(34) Sentential negation does not cause a negative island effect (cf $31 \mathrm{~b}$ ):

$\checkmark$ Which student didn't read a book from which library? 
Similarly, we note that the contrasts in (31-32) cannot be due to a general Beck (2006) focus intervention effect between the in-situ wh-phrase and C. As we saw in section 2.1, high interveners in superiority-obeying questions do not cause intervention effects, including other negative interveners such as no one and never. As a result, it cannot be the case that the surface in-situ wh in these examples is interpreted in-situ at LF, projecting alternatives all the way up to C. If that were the case, we would predict the examples with higher interveners in (35) to be ungrammatical, contrary to fact. Interpreting these wh-phrases insitu at LF would not be able to explain the contrast between the grammatical (35a-b) on the one hand and the ungrammatical (31b) and (32b) on the other hand. ${ }^{19}$

\section{(35) No intervention effect with higher intervener:}

a. $\checkmark$ Which student didn't read a book from which library?

b. $\quad \checkmark$ Which collector only APPRAISES pictures of which president?

Additionally, no intervention effect is observed when a focus-sensitive operator occurs inside the potentially pied-piped region but below the intervener, as in (36).

\section{(36) No intervention effect with intervener below wh:}
a. $\checkmark$ Which student read which book containing no princesses?
b. $\checkmark$ Which student read which book discussing only princesses?

Finally, no intervention effect arises when no heads a coargument to the wh-phrase in a double-object construction such as (37) below. ${ }^{20}$ As in (26) above, the negative head no occurs above the in-situ wh-word. However, unlike in (26), intervention does not occur in this structure.

\section{(37) No intervention effect with no in a coargument:}

a. Context: Professors White and Black are co-teaching a syntax class. Over the break, each student in the class was expected to write three book reports. Each

\footnotetext{
${ }^{19}$ Also recall that, for the pair-list readings we target here, the surface in-situ wh-phrase cannot be interpreted in-situ through a choice-function mechanism such as Reinhart (1998). See also footnote 14.

${ }^{20}$ We thank an anonymous reviewer for bringing examples similar to (37) to our attention.
} 
book report had to be submitted to both professors for grading. Each student wrote three book reports, but oddly enough, each student submitted her three book reports to only one of the two professors. You have looked at the grading book. So tell me, what I want to know is:

b. $\checkmark$ Which student submitted no book report to which professor?

The important difference between these two structures is in the pied-piping options available to them, and in particular that no book report to which professor in (37) is not a possible QP and therefore not a possible target for covert pied-piping. The cases of intervention we observe in examples such as (26), then, are precisely those where the intervener is contained within a constituent which is a pied-piping candidate for the wh-phrase.

Combining all our findings, we observe intervention effects in questions in which the intervener occurs in a small region above the $w$ h as in (31b) and (32b), but not in questions that contain a high intervener such as (35) and (37). Therefore, we know that the interveners in (31b) and (32b) are inside intervenable regions but the ones in (35) and (37) are not. Consequently, it cannot be the case that the wh in the superiority-obeying questions that we are examining remains in-situ and is interpreted via Rooth-Hamblin alternative computation between its base-generated position and C. Instead, the pattern of intervention effects that we find is consistent with the presence of covert pied-piping: intervention occurs only when the intervener is placed inside QP and above wh, as in (38). This is predicted if the derivation of superiority-obeying questions involves covert movement of the lower wh to C at LF, with pied-piping of a constituent inside of which Rooth-Hamblin alternatives are computed between wh and $\mathrm{Q}$.

\section{(38) No causes intervention effect because it is in intervenable region inside QP:}
a. $\checkmark$ Which student read [QP $\mathrm{Q}$ a book from which library]?
b. ${ }^{*}$ Which student read [QP $\mathrm{Q}$ no book from which library]?

Cable's (2010) theory predicts that VPs and larger sized constituents cannot form QPs in English. Thus interveners at the VP level and higher will not be in an intervenable region, 
explaining the lack of intervention by higher interveners as in (39a). Similarly, since intervention only affects the region between the wh-word and $Q$, this approach also explains the lack of intervention in (39b). ${ }^{21}$

\section{No intervention effect when intervener is outside intervenable region:}
a. $\checkmark$ Which student didn't read [QP $\mathrm{Q}$ a book from which library]?
b. $\quad \checkmark$ Which student read [QP Q which book containing no princesses]? (=36a)

Finally, the evidence from intervention presented here allows us to further pinpoint the size of covert pied-piping. Assuming that the options for covert pied-piping parallel the options for overt pied-piping in a singular wh-question, we imagine the covert pied-piping options in (27), repeated below. Note that only (27a) predicts the intervention effect that we have observed. If $(27 \mathrm{~b}-\mathrm{c})$ were possible candidates for covert pied-piping, we would predict no intervention effect in (38b). Hence, we must conclude both that covert piedpiping exists and that it necessarily chooses the largest option among those available for overt pied-piping.

\section{(27) Different covert pied-piping options predict different intervenable regions:}

Which student read no book from which library?
a. [QP Q Which student] read [QP Q no book from which library].
b. [QP Q Which student] read no book [QP $Q$ from which library].
c. [QP Q Which student] read no book from [QP Q which library].

\footnotetext{
${ }^{21}$ An anonymous reviewer asks whether we predict intervention effects to occur inside these larger piedpiped constituents in languages that allow for overt clausal pied-piping. We believe that the answer to this question is no, because secondary wh-movement may target the edge of the pied-piped clause (see e.g. Romanian data in Ratiu (2005)). (Snejana Iovtcheva (p.c.) notes that clausal pied-piping with secondary wh-movement also occurs overtly in Bulgarian.) Furthermore, Kotek (2013) argues that similar partial whmovement to the edge of a clause occurs covertly in the interpretation of in-situ wh-words inside clausal islands. Kotek (2013) notes that in such questions, intervention occurs when the intervener is above the island, but not when it is inside it. This is explained if the wh can move covertly to the edge of the island, above any interveners inside it, but it cannot escape the island, thus remaining sensitive to intervention effects above the island. See also Kotek and Hackl (2013) for additional evidence of partial wh-movement to projections with propositional type.
} 
To summarize the findings of this section, we have presented evidence for the existence of covert pied-piping from the pattern of intervention effects in superiority-obeying English multiple wh-questions. We showed that the pattern is predicted only if we assume a local region of focus alternative computation: intervention occurs only in a small region above the surface in-situ wh-phrase. This pattern does not support a theory where these surface in-situ wh-phrases are generally sensitive to negative islands; nor does it support a theory where such wh-phrases are interpreted in-situ and project Rooth-Hamblin alternatives from its base-generated position to C. Instead, this pattern is predicted by Cable's (2010) theory of pied-piping. This theory predicts both the size of pied-piping that should be possible, and that inside the covertly pied-piped constituent we should find a region that is sensitive to intervention effects, under Beck's (2006) theory of focus intervention effects. However, unlike overt pied-piping, covert pied-piping must choose the largest possible candidate for movement and smaller constituents are not viable candidates. In the next section, we discuss the reasons for this discrepancy between the sizes of overt and covert pied-piping.

\section{Pied-piping and the interfaces}

In this section we address the differing sizes of pied-piping in overt vs. covert movement. As is well known, overt pied-piping can target constituents of varying sizes, as shown in (40). Furthermore, we have seen in example (19)—repeated below as (41) — that targeting a smaller constituent for pied-piping can rescue a question from an intervention effect.

\section{(40) Options for overt pied-piping:}
a. [QP Q A picture of which president] does Jim own _ ?
b. [QP Q Of which president] does Jim own a picture _ ?
c. [QP Q Which president] does Jim own a picture of _ ? 
(41) No intervention if the intervener is not inside the pied-piping constituent:
a. * [QP Q No pictures of which president] does Jim own _ ?
b. $\quad \checkmark[\mathrm{QP}$ Q Of which president] does Jim own no pictures __ ?
c. $\checkmark[\mathrm{QP} Q$ Which president] does Jim own no pictures of _ ?

In contrast to this state of affairs in overt pied-piping, to correctly predict the pattern of intervention effects we observed in covert pied-piping it must be the case that only the largest QP available in (40), observed in (40a), is targeted for movement in the case of covert pied-piping. If smaller constituents could also be targeted for movement, we would predict no intervention effects at all in the superiority-obeying questions that we surveyed above. That is, in a multiple wh-question like (42), only (42a) is a valid QP that can be attracted by $C$; the QPs in $(42 b-c)$ cannot be available targets for movement. (Here, $\bigcirc$ is used to indicate derviations which the grammar considers, and $\times$ indicates those which the grammar does not consider.)

\section{(42) Only the largest covert pied-piping correctly predicts the section 3 pattern:}

Which student read no book from which library?
a. $\bigcirc$ [QP $Q$ Which student] read [QP $\mathrm{Q}$ no book from which library].
b. $\times\left[{ }_{Q P} Q\right.$ Which student] read no book [QP $Q$ from which library].
c. $\times\left[{ }_{\mathrm{QP}} \mathrm{Q}\right.$ Which student] read no book from [QP $\mathrm{Q}$ which library].

This discrepancy is particularly puzzling since most speakers report a preference for the smaller overt pied-piping options in $(40 \mathrm{~b}-\mathrm{c})$ over $(40 \mathrm{a})$. Thus we find that the least preferred among the overt pied-piping options is the only candidate for covert pied-piping, (42a). Moreover, as we've seen, the upper bound on the possible size of QP is consistent across overt and covert pied-piping: in both cases, QPs formed by merging Q with VP or with a larger structure are ruled out. Consequently, we suggest that possible QP sizes are the same across overt and covert pied-piping.

The discrepancy we observe in the pattern of intervention effects results from the different constraints that overt and covert pied-piping must satisfy. While overt pied-piping is 
subject to both LF and PF constraints, covert pied-piping is subject to LF constraints only. That is, overt pied-piping feeds both LF and PF, and therefore must satisfy constraints at both interfaces. Covert pied-piping only feeds LF and thus shows us the true preference with regard to pied-piping: LF prefers to pied-pipe as large a constituent as possible, but in overt movement, this preference can be overridden by the needs of PF.

In particular, it has been noticed by several researchers that overtly-moved wh-phrases prefer to be near the left edge of the clause (Horvath, 2007; Heck, 2008, 2009; Richards, 2010; Cable, 2012, 2013, a.o.). Richards (2010) proposes that this is a linearly-oriented preference PF interface constraint. He defines this constraint as a requirement on the prosody of whquestions, (43) and shows that it can be satisfied in different languages in different wayseither through overt movement or through manipulation of prosodic phrase boundaries in wh-in-situ languages.

(43) Prosody condition on wh-questions (Richards, 2010):

Given a wh-phrase $\alpha$ and a complementizer $\mathrm{C}$ where $\alpha$ takes scope, create a level of phrasing on which $\alpha$ and $\mathrm{C}$ are not separated by any phonological phrase boundaries.

In English, the interpreting complementizer is always to the left and wh-movement is invoked to satisfy (43). Therefore the result of this prosody condition is a requirement for leftness, as in (44):

\section{(44) The leftness preference of $w h$-phrases: a PF constraint}

Wh-phrases prefer to be closer to the left edge of the clause.

We argue that the effects of this constraint are observable in English overt pied-piping. For example, consider the options for overt pied-piping in (40), repeated below. While all three pied-piping options are strictly speaking grammatical, many speakers report a preference for $(40 \mathrm{~b}-\mathrm{c})$ over $(40 \mathrm{a})$. This preference correlates with the fact that the wh-word is significantly further away from the clause edge in (40a) than in (40b-c). 


\section{(40) Options for overt pied-piping:}
a. [QP Q A picture of which president] does Jim own $?$
b. [QP Q Of which president] does Jim own a picture _ ?
c. [QP $\mathrm{Q}$ Which president] does Jim own a picture of __ ?

Example (40) makes clear that all theories of pied-piping must allows for some measure of optionality with regard to the satisfaction of Richards's (2010) prosody constraint (our leftness constraint). In Cable's (2010) work, the syntax allows several different options for the merger site of the $\mathrm{Q}$ morpheme, as we have shown above. This grammatical mechanism must then interact in some way with the prosody constraint to predict that some positions for $Q$ are preferred over others.

Further examples help clarify that it is the linear distance from the left edge of the clause that matters here, not the size of the pied-piping constituent or the depth of the embedding of the wh-word within. Consider the examples in (45) below. Although the syntactic and semantic content of the two examples are very similar, speakers report a difference in their acceptability. Example (45a), which contains a large pied-piping constituent with the wh deeply embedded is judged by speakers to be perfectly acceptable. This contrasts sharply with (45b), which is ungrammatical. This contrast is attributed to the fact that the wh is near the left edge of the pied-piping constituent in (45a) but not in (45b) (data from Cable, 2012).

\section{(45) Large pied-piping is grammatical if the wh is at the edge of the moved constituent:}
a. $\quad \checkmark[\mathrm{QP} Q$ [[Whose brother]'s friend]'s father] did you see?
b. * ${ }_{\mathrm{QP}} \mathrm{Q}$ The father of [[whose brother]'s friend] ] did you see?

Furthermore, even larger pied-piping in which the wh is even further embedded, as in (46), remains grammatical, so long as the wh-word is near the left edge of the pied-piping constituent. Thus, we see that PF does not restrict large pied-piping per se, but rather only pied-piping in which wh is not near the edge of the moved constituent. 
(46) Pied-piping remains grammatical even with very deep embedding of wh in large QP:
a. $\quad \checkmark$ [QP Q [[[Whose brother]'s friend]'s father]'s boss] did you see?
b. $\quad \checkmark[\mathrm{QP} Q$ [[[[Whose brother]'s friend]'s father]'s boss]'s secretary] did you see?

This general preference of $w h$-phrases to be at the left edge (44) also results in corrollaries such as Heck's $(2008 ; 2009)$ Edge Generalization:22

(47) The Edge Generalization (Heck 2008: 88, Heck 2009: 89)

If $\alpha$ pied-pipes $\beta$ (and movement of $\alpha$ to the edge of $\beta$ is grammatically possible), then $\alpha$ must be at the edge of $\beta$.

Heck's Edge Generalization explains cases of secondary wh-movement as in (48a). Here, a QP containing wh is pied-piped to the edge of a question, and following this movement wh must move to the edge of the pied-piping constituent. The general possibility of such movement for degree heads is illustrated by (48c) (data from Cable, 2012).

\section{(48) Secondary wh-movement of degree wh predicted by Edge Generalization:}
a. $\checkmark[[$ How big] a car $]$ did Bill buy?
b. * [A [how big] car] did Bill buy?
c. $\checkmark$ Bill would never buy [[that big] a car].

Again, this requirement that wh appear near the edge of QP appears to be a PF requirement, not one of structure-building or interpretation. An LF for a question as in (49a), where we see that secondary wh-movement is not possible, is also interpretable. (49c) shows that in this case, secondary wh-movement is generally not possible (data from Cable, 2012). From this point of view, then, secondary wh-movement is motivated solely by PF, not by LF.

\footnotetext{
${ }^{22}$ We note that both Heck $(2008 ; 2009)$ and Cable $(2007 ; 2010)$ have developed syntactic accounts of the Edge Generalization, which explains it through interactions in the narrow syntax. For Heck, the Edge Generalization follows from Attract Closest, while for Cable it is attributed to the Phase Impenetrability Condition and the need for $\mathrm{Q}$ to agree with wh. It is beyond the scope of this paper to decide which approach to the Edge Generalization is correct.
} 

pretable:
a. $\quad \checkmark$ [In [whose honor]] was this made?
b. * [[Whose honor $]$ in $]$ was this made?
c. * This was made [[Dave's honor] in].

To summarize, we have seen a PF preference for having wh near the edge of an overtly pied-piped constituent. We have also seen that this is not an absolute requirement: larger pied-piping as in (40a) are accepted by most speakers, even if they are found to be less wellformed than smaller pied-piping options (40b-c). Furthermore, we have seen that the PF preference is not for smaller pied-piping as a general rule, but rather for realization of the wh-word as far left as possible. This was demonstrated by the large possessive pied-piping in (45-46).

We propose that this PF constraint in (44) is the source of differences in size between pied-piping for overt and covert movements. By hypothesis, covert movement only affects the LF interface, and therefore the choice of covertly-moved QP size will not affect the PF linearization: ${ }^{23}$

\section{(50) The choice of covertly-moved QP size does not affect the PF linearization:}

Which student read a book from which library?
a. [QP Q Which student] read [QP Q a book from which library].
b. [QP Q Which student] read a book [QP $Q$ from which library].
c. [QP Q Which student] read a book from [QP Q which library].

\footnotetext{
${ }^{23}$ But note that overt secondary $w h$-movement does still apply to PF-in-situ wh-phrases:

(i) a. $\checkmark$ I know [which student bought [[how big] a car]].

b. * I know [which student bought [a [how big] car]].

This contrast shows that surface in-situ wh-words are still subject to the general leftness preference (44). The choice of QP size in (50), on the other hand, simply cannot affect the PF output, due to the general unavailability of multiple wh-fronting in English.
} 
The results of section 3 thus help disentangle the preferences of PF vs. LF with regard to pied-piping size. The intervention pattern we found supports the conclusion that only the largest pied-piping is possible for covert movement. Hence, we learn that the preference of LF and Core Syntax is for larger pied-piping. This preference can be overridden by the PF constraints that govern overt pied-piping such as (44), resulting in the complex patterns of pied-piping that we have seen in this section.

Formally, this preference for larger covert pied-piping could be thought of as derived from a top-down application of the constraint Attract Closest (Relativized Minimality: Rizzi 1990; Minimal Link Condition: Chomsky 1995, 2000; also Shortest Move: Chomsky 1993). That is, $C$ probes from above for positions where $Q$ could grammatically be merged to form a QP and attracts the first Q-compatible constituent that it finds. ${ }^{24}$ In Cable's (2010) system, these possible positions are constrained as shown in (50), ruling out large pied-piping of VPs or larger material. Due to the top-down nature of probing (Chomsky, 2000), this would yield a preference of Core Syntax for larger QPs.

This kind of logic, where attraction operations must apply to a larger constituent which may itself contain a possible second target of movement is prevalent in the linguistic literature. For example, it is how Chomsky (1964) and Ross (1967) define the A-over-A principle, requiring that operations which may in principle apply to a larger target or to a smaller target contained within the larger target apply only to the larger target. We propose that in cases of overt movement, this operation is in competition with conditions on the prosody of wh-questions, as in Richards's (2010) work. Since these conditions only affect movement that has consequences for the PF branch-that is, for overt movement-they are inactive for the purpose of deriving covert pied-piping. In that case, we predict that only Attract Closest is at play, and therefore that only the largest pied-piping option is available in the

\footnotetext{
${ }^{24}$ In this variant, then, it may be the case that $\mathrm{QP}$ is not at all constructed, but instead what matters is Qcompatibility, in Cable's (2010) system. Another option is that Q is countercyclically merged to produce a QP for C to Attract. Alternatively, under a left-to-right approach to structure building as in Phillips $(1996,2003)$, such a merger of $Q$ would in fact not be countercyclic. Because $Q$ is silent in English, these two variants are difficult to tell apart and we will not attempt to distinguish between them here.
} 
grammar. $^{25}$

The end result of this discussion is somewhat different from the proposal in Cable (2010). In Cable (2010), all QPs derived from the grammatical merger of a Q-particle are predicted to be equally good. The grammaticality pattern observed here shows us that only the largest pied-piping option is considered for pied-piping by LF and Core Syntax. This choice can be overridden by the PF constraint preferring that wh be closer to the left edge of the clause, thus making smaller pied-piping options available for overt pied-piping only.

\section{Conclusion}

In this paper, we address the question of whether covert movement triggers pied-piping. Unlike pied-piping triggered by overt movement, covert pied-piping is not reflected in surface word order. Instead, here we utilized the unique syntax/semantics of pied-piping constituents to form a diagnostic for the existence and size of covert pied-piping. We argued that covert movement does trigger pied-piping, and that the preference of covert piedpiping is for movement of larger constituents, unlike overt pied-piping.

The core data discussed in this paper exhibits a previously unobserved pattern of focus intervention effects in English multiple wh-questions. We showed that a small region above the surface-in-situ wh-word in superiority-obeying multiple questions is intervenable - that is, the insertion of a focus-sensitive operator in this region causes the disappearance of the multiple question's pair-list interpretation.

In this paper we adopt Beck's (2006) theory of focus intervention effects which affect regions of Rooth-Hamblin alternative computation. Following Cable (2007), the region between a wh-word and the edge of its pied-piping constituent will be a region of alternative computation and therefore be intervenable. Thus the existence of intervention in

\footnotetext{
${ }^{25}$ One could also imagine another proposal similar in spirit, which involves a transderivational application of Attract Closest. That is, we could imagine the grammar considering the three derivations in (50) in parallel, differing only in the position where $\mathrm{Q}$ is merged. The derivation with the largest QP (50a) will result in the optimal satisfaction of Attract Closest-type constraints for the probing of QP by C. See Reinhart (2006) for more on transderivational constraints and motivations for them.
} 
these small regions above the surface-in-situ wh-word constituents evidence for a piedpiping constituent around the wh-word. Alternative explanations were also discussed and shown to not derive the observed contrasts. The contrasts observed here therefore form an argument for the existence of covert pied-piping.

Furthermore, the diagnostic employed here helps determine the size of covert pied-piping. Whereas in overt movement, different sized constituents containing the wh-phrase can be chosen for pied-piping, we showed that in covert movement, only the largest pied-piping constituent is considered by the grammar. We explain this contrast in terms of the different interface constraints which are fed by overt and covert movement: overt movement feeds both PF and LF, while covert movement feeds only LF. We yield the conclusion that the true preference of Core Syntax and LF is for pied-piping larger constituents. In overt movement, however, certain surface-oriented PF constraints are shown to override this choice of pied-piping.

The observations presented here also constitute a further argument for the Beck (2006) theory of focus intervention effects. We extend the empirical scope of the phenomenon of "focus intervention" in English—building on previous work on superiority-obeying and superiority-violating questions (Pesetsky, 2000; Beck, 2006) and intervention in overt piedpiping (Cable, 2007) —and show that this novel data is best accounted for in Beck's theory. At its core, this amounts to further empirical support for Beck's thesis that the alternatives utilized for focus interpretation (Rooth, 1985, 1992) and alternatives utilized for whquestion interpretation (Hamblin, 1973) are the same formal objects and that they interact in non-trivial ways. 


\section{References}

Arregi, Karlos. 2002. Focus on Basque movements. Doctoral Dissertation, Massachusetts Institute of Technology.

Beaver, David, and Brady Clark. 2008. Sense and sensitivity: How focus determines meaning. Wiley-Blackwell.

Beck, Sigrid. 1995. Negative islands and reconstruction. In On extraction and extraposition in German. John Benjamins.

Beck, Sigrid. 1996. Quantified structures as barriers for LF movement. Natural Language Semantics 4.

Beck, Sigrid. 2006. Intervention effects follow from focus interpretation. Natural Language Semantics 14:1-56.

Beck, Sigrid, and Shin-Sook Kim. 2006. Intervention effects in alternative questions. Journal of Comparative German Linguistics 9:165-208.

Büring, Daniel. 1996a. Drinking, accents, and negation. In Proceedings of Workshop on Focus, ed. Elena Benedicto, Maribel Romero, and Satoshi Tomioka, number 21 in University of Massachusetts Occasional Papers in Linguistics, 37-50. UMass, Amherst: GLSA.

Büring, Daniel. 1996b. A weak theory of strong readings. In SALT VI, ed. Teresa Galloway and Justin Spence.

Cable, Seth. 2007. The grammar of Q. Doctoral Dissertation, Massachusetts Institute of Technology.

Cable, Seth. 2010. The grammar of Q: Q-particles, wh-movement, and pied-piping. Oxford.

Cable, Seth. 2012. Pied-piping: introducing two recent approaches. Language and Linguistics Compass 6:816-832.

Cable, Seth. 2013. Pied-piping: comparing two recent approaches. Language and Linguistics Compass 7:123-140.

Chomsky, Noam. 1964. The logical basis of linguistic theory. In Proceedings of the 9th International Congress of Linguists. 
Chomsky, Noam. 1973. Conditions on transformations. In A festschrift for Morris Halle. New York: Holt, Reinhart, and Winston.

Chomsky, Noam. 1993. A minimalist program for linguistic inquiry. In The view from Building 20, ed. Kenneth Hale and Samuel Jay Keyser. MIT Press.

Chomsky, Noam. 1995. The minimalist program. MIT Press.

Chomsky, Noam. 2000. Minimalist inquiries: the framework. In Step by step: Essays on minimalist syntax in honor of Howard Lasnik. MIT Press.

Culicover, Peter W. 1992. Topicalization, inversion, and complementizers in English. In Going romance and beyond. OTS Working Papers in Linguistics 91.

Dayal, Veneeta. 2002. Single-pair versus multiple-pair answers: wh-in-situ and scope. Linguistic Inquiry 33.

Drubig, Hans Bernhard. 2000. Towards a typology of focus and focus constructions .

Erlewine, Michael Yoshitaka, and Hadas Kotek. to appear. Intervention in focus piedpiping. In Proceedings of NELS 43. URL http://semanticsarchive.net/Archive/ WIzNzViN/.

Fox, Danny, and Martin Hackl. 2006. The universal density of measurement. Linguistics and Philosophy 29.

Grohmann, Kleanthes K. 2006. Top issues in questions: Topics-topicalizationtopicalizability. In Wh-movement: Moving on, ed. Lisa Lai-Shen Cheng and Norbert Corver. MIT Press.

Hagstrom, Paul. 1998. Decomposing questions. Doctoral Dissertation, Massachusetts Institute of Technology.

Hamblin, Charles. 1973. Questions in Montague English. Foundations of Language 10:41-53. Heck, Fabian. 2008. On pied-piping: wh-movement and beyond. Berlin: Mouton de Gruyter. Heck, Fabian. 2009. On certain properties of pied-piping. Linguistic Inquiry 40:75-111. Herburger, Elena. 2000. What counts: focus and quantification. MIT Press.

Horvath, Julia. 1986. FOCUS in the theory of grammar and the syntax of Hungarian. Foris, Dordrecht. 
Horvath, Julia. 2007. Separating "focus movement" from focus. In Phrasal and clausal architecture. John Benjamins.

Huang, Cheng-Teh James. 1982. Move wh in a language without wh movement. The Linguistic Review 1.

Karttunen, Lauri. 1977. Syntax and semantics of questions. Linguistics and Philosophy 1:3-44.

Kotek, Hadas. 2013. Intervention out of islands. Manuscript, MIT.

Kotek, Hadas. forthcoming. Wh-fronting in a two-probe system. Natural Language $\mathcal{E}$ Linguistic Theory .

Kotek, Hadas, and Martin Hackl. 2013. A new syntax for multiple wh-questions: Evidence from real time sentence processing. Manuscript, MIT.

Kotek, Hadas, Yasutada Sudo, and Martin Hackl. 2012. Many readings of most. Presented at Chicago Linguistics Society (CLS) 48.

Kratzer, Angelika, and Junko Shimoyama. 2002. Indeterminate pronouns: the view from Japanese. In The Proceedings of the Third Tokyo Conference on Psycholinguistics (TCP 2002).

Kuno, Susumu, and Jane J. Robinson. 1972. Multiple wh questions. Linguistic Inquiry 3.

Kuno, Susumu, and Kenichi Takami. 1997. Remarks on negative islands. Linguistic Inquiry

Mayr, Clemens. 2010. The role of alternatives and strength in grammar. Doctoral Dissertation, Harvard.

Mayr, Clemens. to appear. Intervention effects and additivity. Journal of Semantics .

Pesetsky, David. 2000. Phrasal movement and its kin. MIT Press.

Phillips, Colin. 1996. Order and structure. Doctoral Dissertation, Massachusetts Institute of Technology.

Phillips, Colin. 2003. Linear order and constituency. Linguistic Inquiry .

Ratiu, Dafina. 2005. Questions multiples en Roumain. Master's thesis, Université de Nantes.

Reinhart, Tanya. 1998. Wh-in-situ in the framework of the Minimalist Program. Natural Language Semantics 6. 
Reinhart, Tanya. 2006. Interface strategies. MIT Press.

Richards, Norvin Waldemar III. 2010. Uttering trees. MIT Press.

Rizzi, Luigi. 1990. Relativized minimality. MIT Press.

Rooth, Mats. 1985. Association with focus. Doctoral Dissertation, University of Massachusetts, Amherst.

Rooth, Mats. 1992. A theory of focus interpretation. Natural Language Semantics 1:75-116.

Ross, John Robert. 1967. Constraints on variables in syntax. Doctoral Dissertation, Massachusetts Institute of Technology.

Ross, John Robert. 1984. Inner islands. In Proceedings of BLS 10.

Rullmann, Hotze. 1995. Maximality in the semantics of wh-constructions. Doctoral Dissertation, University of Massachusetts Amherst.

Sauerland, Uli, and Fabian Heck. 2003. LF-intervention effects in pied-piping. In Proceedings of NELS 33.

Simpson, Andrew. 2000. Wh-movement and the theory of feature-checking. John Benjamins.

Simpson, Andrew, and Tanmoy Bhattacharya. 2003. Obligatory overt wh-movement in a wh-in-situ language. Linguistic Inquiry .

Szabolcsi, Anna, and Frans Zwarts. 1993. Weak islands and an algebraic semantics for scope taking. Natural Language Semantics 1.

Szendrói, Kriszta. 2003. A stress-based approach to the syntax of Hungarian focus. The Linguistic Review .

Tomioka, Satoshi. 2007. Pragmatics of LF intervention effects: Japanese and Korean interrogatives. Journal of Pragmatics 39.

Truckenbrodt, Hubert. 2013. An analysis of prosodic F-effects in interrogatives: prosody, syntax, and semantics. Lingua 124. 